SHS Web of Conferences 7, 02001 (2014)

DOI: $10.1051 /$ shsconf / 20140702001

(C) Owned by the authors, published by EDP Sciences, 2014

\title{
A Study on Innovative Management of Universities' Postgraduate Associations in the New Era
}

\author{
Li Wei \\ Graduate school, Huazhong Agricultural University, 430070 Wuhan Hubei, China
}

\begin{abstract}
Postgraduate Association is a higher community among college student organizations, and it is a significant carrier for universities' ideological and political construction and campus culture construction in the new era. While in the current, Postgraduate Association, exists a series of problems, like imperfect internal management, mispositioning of organizational development, weak services and low participation of activities. In order to promote the development of postgraduate association, it is necessary to innovate management model of Postgraduate Association by standardizing the management, clearing the development target of the association, enhancing service capabilities, enriching activities and so on.
\end{abstract}

Keywords. universities; management model; culture construction

Postgraduate Association is a voluntary campus mass organization in which postgraduate goes on selfeducation, self-management and self-service. The quality of activities organized by it will directly affect all aspects of graduate education, development and so on. In recent years, with the growth of the scale of postgraduate education and the need of campus culture construction, Postgraduate Campus Association has become the main carrier of academic, ideological, political, and cultural construction, which makes it an important part of the current personnel universities postgraduate training.

\section{Postgraduate Association as an important carrier for postgraduate management}

In recent years, along with the rapid development of postgraduate education, the scale of Postgraduate Association is also rapidly expanding. At the same time, it grows into a significant carrier for postgraduate management.

\subsection{Postgraduate Association as an important platform for ideological and political construction}

Ideological and political construction is a significant part of higher education. Therefore, deepening and improving postgraduates' ideological and political construction, increasing ideological and political accomplishment, fostering them into Chinese socialism with Chinese characteristics' qualified builders and loyal successor. It is of great and far-reaching significance to build harmonious socialist society, boosting the grand goal of socialist modernization, ideological and political 
construction should be a continuing work, as under the current circumstance, the social economy moves forward, postgraduates' ideological and political consciousness is easily be affected by all kinds of bad influences, and their view towards life, the world and values are easily changed. However, undergraduate education mainly depend on political courses and instructors' efforts, postgraduates focus more on their study and scientific researches, meanwhile, numbers of instructors who solely work on postgraduates' ideological and political education are limited. Thus, it is necessary to hold relative activities through Postgraduate Association like Party Affairs Construction Office of Postgraduates and so on.

\subsection{Postgraduate Association as an important organization form for the style of study construction of postgraduates}

It is postgraduates' main job to conduct scientific researches, especially for some research universities, postgraduates play a significant role in the innovation of universities' scientific researches. Take Huazhong Agricultural University as an example, in recent years, issued papers and applied patents by postgraduates occupy $80 \%$ percent of the total sums, making postgraduates a fresh troop for the innovation of universities' scientific researches. Although academic atmosphere of postgraduates has become an important component of universities' campus culture, shortage of management culture, academic system and academic activities results in dilemmas in academic culture of postgraduates such as academic moral problems, loss of academic spirit, decline of innovative ability of academy and absence of academic rights.[1] In order to change such dilemmas, we must open up and make pointed references when innovating academic culture construction of postgraduates, making academic associations like Postgraduate Science and Technology Association the major force in boosting academic culture, and organizing academic activities for postgraduates.

\subsection{Postgraduate Association as an important way to build campus culture}

In a large extent, university campus culture resembles the university's strength and level, and for most research universities, the number of postgraduates gradually exceeds undergraduates and Postgraduate Association has become an important community in university. Moreover, postgraduates come from different universities nationwide, different sources make them of more plyability and multiplicity, this feature has positive meaning to enrich campus culture construction, because postgraduates have relative less time to organize activities compared to undergraduates, and most of them concentrate on study and scientific researches, hence, organizing some distinctive campus activities, also as a meaningful component, can significantly enrich postgraduates' life, foster their characteristics and specialties, and improve their innovative ability. What's more, Postgraduate Association is the intermediate force of all kinds of campus organizations. In addition, Postgraduate Science and Technology Association, represented by Postgraduate Student Union, bridge the university and postgraduates, putting forward advices to the university and managerial departments on behalf of postgraduates, and maintain their rights.

\section{Problems existed in Postgraduate Association}

Despite of the important role Postgraduate Association playing in the education and management of postgraduates. There are following problems:

\subsection{Imperfection of inner management of Postgraduate Association}

First of all, the inner management of universities' Postgraduate Association currently mainly depend on self-management, so they often face problems such as the imperfect selecting system of inner members, lacking funds, lack of experiences of relative majors and activities, which lower the 
efficiency and quality of those activities.[2] Secondly, In terms of the organization structure, postgraduate student union is the main department of Postgraduate Association, and only some universities set up Postgraduate Youth League Committee, Postgraduate Science and Technology Association, but the management is still loose, and the structural line is also unclear. Considering of members, postgraduates joining in student communities is mainly based on personal interests and hobbies while lack of expertise and experiences. And most of master students' length of schooling is of two or three years, so the actual working time in the community is short, along with connection problem. Thirdly, most Postgraduate Association have no stable places and fund resources, making it hard for relative activities to achieve the best effect, and thus limiting the expansibility and continuity of those activities. Fourthly, from the aspect of supervision and management mode, these communities are of no strict supervision and management mechanism and special supervising department which go against forming effective supervision. Most universities haven't held representative conferences of postgraduates, the management is stereotyped, and inner regulation is old-fashioned, the development is seriously limited.

\subsection{Inappropriate target for the development of the association}

The development of Postgraduate Association needs to find a clear position, while the Association is still lack of understanding to inner and external environment. There is no comprehensive and objective understanding of the overall situation and growing trend to the development during the process of founding and developing, and they can not comprehend the association's inner and external environment and see the association's advantages and disadvantages, this makes it hard to find an appropriate position for the association and set up long-term and short-term target.[3] Some communities lack of understanding to their own development mandate, so important tasks that founders haven't finished can only be expected to be done by successors, while successors cannot realize their responsibilities, nor can they consider the inner revolution under correspondent external environment, the development of the whole association then face a plight. Some Postgraduate Association even face the problem of not be supported by the school and postgraduates because they haven't functioned the way they should, and finally died out along with loss of their good work and experiences made.

\subsection{Poor service ability of the association}

Postgraduate Association is a self-service organization by postgraduates, the tenet is to provide service to postgraduates, including ideologic and political, academic, daily cultural and other demands and service. Moreover, Postgraduate Association communicates with the university and other organizations on behalf of postgraduates, making efforts to maintain their rights and provide all kind $\mathrm{s}$ of considerable services. But Postgraduate Association is currently constricted by funds, talents and managerial experience. They also face many problems in organizing, planning and popularizing activities. So they can not satisfy their members and postgraduates' needs, and thus their functions are not reflected.[4] Postgraduate Association in some universities is an autonomous organization nominally, while actually be controlled by the university and never organize activities actively, under such circumstance, it is can not really possible to realize the essence of the "three guidelines of selfmanagement".

\subsection{Low participation of activities organized by Postgraduate Association}

Postgraduates' pressures of scientific researches and the background of specialization lead to the low participation of activities. Most undergraduates entered college through the college entrance examination, they are always enthusiastic for college life, and willing to actively take part in community activities. On the contrary, the source of postgraduates is variant and of high inhibitive 
ability. Some are recommended for admission as postgraduates, some directly take part in the postgraduate entrance exams after graduation from the college, and some have working experiences, there are also some people are part-time postgraduates. The huge difference of sources results in overall differences as well as obvious differences in the view toward life, the world and values. In addition, part-time postgraduates and students who have working experiences show little interest in student work, and for other full-time postgraduates, some of them concentrate on the academic research, and are unwilling to spend time in taking part in activities organized by Postgraduate Association. And others have already participated in student work as undergraduates, they have achieved relative experiences and are not willing to do it again. Hence, members that join Postgraduate Association spontaneously are not enough, and few people participate in activities. The above fact leads to the low participation of Postgraduate Association.

\section{Suggestions for perfection the management of postgraduate student community in the new era}

To solve problems Postgraduate Association encountered in the development, it is necessary to innovate the management mechanism of Postgraduate Association, to form a scientific and reasonable management mode, and to ensure the continuously development of activities organized by Postgraduate Association.

\subsection{Standardizing Postgraduate Association's management system}

A standardized management system is the premise of the association's development. As the scale and demand of postgraduates are increasing, Postgraduate Association will have some changes. In terms of the loose management of college's Postgraduate Association, the university needs to clear-out the relationship among organizations of Postgraduate Association as well as inside the community so as to avoid the confusion. Taking Postgraduate Association of Huazhong Agricultural University as an example, there are totally six school-level organizations, they are Party Construction Office of Postgraduates, Work Committee of Postgraduate, Postgraduate Student Union, Postgraduate Science and Technology Association, Career Development Center of Postgraduate and Postgraduate Media Center. Postgraduate Student Union is the earliest one that was set up and is relatively standardized. So activities and duties are clear and can be inherited in good order. What's more, the coordination in different organizations and daily management inside each organization, and the relationship between school-level organizations and department-level organizations also need to be managed through standardization.

\subsection{Improving the service ability of Postgraduate Association}

The service ability of Postgraduate Student community is the foundation of its development. Postgraduate Association can only achieve the approvement and trust of postgraduates, the university and the society through showing excellent service ability. Service ability contains the following aspects, organizing and planing, implementing, mobilizing, advertising and spreading, and so on. Without favorable organization and planning, activities organized by Postgraduate Student community are hard to promote just like water without source. Specific implementation is a crucial part. A good planning program is just a slogan and thought without implementation, and can not be practiced finally. And it is important to mobilize more postgraduates, supervisor, school leaders and other universities and social elites. Impacts of activities need great broadcasting and spreading. Advertising through media like news reports inside and outside of university, websites, Weixin, Sina microblog is a full demonstration that whether an activity can be recognized or not.

\subsection{Perfecting the content of activities organized by Postgraduate Student community}


Abundant contents of activities are the key to the development of Postgraduate Student community. To encourage postgraduates join the community, and attract more postgraduates participate in activities. When organizing activities, Postgraduate Student community should give priority to launch academic communication and foster innovation ability, satisfy postgraduates' diversified demands and advocate creating elegant, healthy and innovative activities. Huazhong Agricultural University holds postgraduate academic annual conference which lasts for more than two months, absorb postgraduates and supervisors from every major.[5] The postgraduate academic annual conference has become a significant brand for school activities.

On the whole, the organization of activities held by Postgraduate Student community plays a more and more important role in postgraduate education and management. It also provide a great platform for postgraduates to actively take part in public affairs, strengthen interpersonal communication, improve organizing ability, leadership, an the ability to communicate. We should pay more attention to Problems existing in the traditional process of organizing activities. Meanwhile, only by innovating the management mechanism of Postgraduate Student community continuously, truly putting people first, organizing abundant activities can we satisfy postgraduates' various demands.

\section{Acknowledgement}

This paper is supported by National Social Science Fund Projects"The effect of higher education shunt mechanism of social stratification and mobility and policy research" (GN:12BSH013); China degree and postgraduate education society funded projects"Studies on the operational mechanism and management mode of education innovation base for graduate of Hubei province" (GN: 2013Y10).

\section{References}

1. Cai Xiaoliang, Li Xueyan. The Predicament and Outlet of Graduate Academic and Cultural Construction[J]. Journal of Chongqing University of Science and Technology (social science edition), 2013 (2):198.

2. Liang Weifeng, et al. Study on the Development and Innovation of Management Mode of Graduate Student Association Activities[J]. Reform and Opening, 2012 (2):103.

3. Wen Wen, Ma Qiang. Study on the Construction of Student Associations in the New Period[J]. Journal of Heze University, 2006 (4):134-135.

4. Yu Zhenzhou, Chou Guiqie, et al. On the Relationship between the Construction of Graduate Student Development of Student Associations and Universities[J]. Journal of Yangzhou University (Higher Education Study Edition), 2009 (2):78.

5. Mei Yingchun, Sun Ying Hui. Analysis of the Organization Work of Graduate Students in Colleges and Universities[J]. The Journal of Liaoning Administration College, 2010 (6):112. 